\title{
Respiratory effects of exposure of shipyard workers to epoxy paints
}

\author{
D Rempel, J Jones, M Atterbury, John Balmes
}

\begin{abstract}
Epoxy resin systems have been associated with occupational asthma in several case reports, but medical publications contain little on the potential adverse respiratory effects of these chemicals in exposed worker populations. To further evaluate the association of workplace exposure to epoxy paints and respiratory dysfunction, the cross workshift changes in pulmonary function and symptoms of 32 shipyard painters exposed to epoxy paints were compared with 28 shipyard painters not exposed to epoxy paints. The prevalence of lower respiratory tract symptoms was significantly higher among painters exposed to epoxy paints compared with controls. Among exposed painters the mean cross workshift change in forced expiratory volume in one second $\left(F^{2} V_{1}\right)$ $(-3.4 \%)$ was greater than the decrement in the non-exposed group $(-1 \cdot 4 \%)$. A significant linear relation was seen between $\%$ decrement in FEV ${ }_{1}$ and hours of exposure to epoxy paints. This study suggests that epoxy resin coatings as used by shipyard painters are associated with increased lower respiratory tract symptoms and acute decrements in $F E V_{1}$. Adequate respiratory protection and medical surveillance programmes should be established in workplaces where exposure to epoxy resin systems occurs.
\end{abstract}

Marine paints must be capable of withstanding extremes of temperature, penetration by salt water, and metal flexion. In shipyards, the use of epoxy resin coatings with these properties has increased

Center for Occupational and Environmental Health, University of California at San Francisco, California, USA

D Rempel, M Atterbury, J Balmes

California Occupational Health Program, Department of Health Services, Berkeley, California, USA J Jones dramatically in the past 20 years. Epoxy resin systems produce strong surface coatings by polymerisation. The resins, usually a glycidyl ether or an epoxidised olefin, are polymerised by a curing agent, usually a complex amine or anhydride. The health hazards associated with epoxy resin systems differ depending on whether the exposure is to the uncured resin, curing agent, carrier solvent, or the cured resin. Some resins are partially cured during manufacture.

Epoxy resin systems and their components are well known skin irritants and sensitisers. ${ }^{1-11}$ There have, however, been few epidemiological studies of the respiratory health of workers exposed to epoxy resin systems. ${ }^{1213}$

The present study evaluated acute changes in the lung function of shipyard painters relative to the use of epoxy paints. The null hypothesis tested was that no cross workshift decrement in forced expiratory volume in one second $\left(\mathrm{FEV}_{1}\right)$ in painters exposed to epoxy resin paints existed compared with a nonexposed group of painters.

\section{Materials and methods}

STUDY POPULATION

Subjects were recruited from among all painters at one shipyard who were working the day and swing shifts on days when three or more painters were using epoxy paints. Because epoxy painting occurred sporadically and usually lasted for only two to five days, a limited number of days were available for study. Employment state and job title were determined by a daily employee roster provided by the employer.

Painters were excluded from the study if they: (1) were exposed to epoxy paints on the preceding day, (2) were foremen or leadmen (exposures were not uniform), or (3) had severe chronic obstructive pulmonary disease (COPD: $\mathrm{FEV}_{1}$ less than $40 \%$ predicted). ${ }^{14}$ Painters were classified as "exposed" or "non-exposed" to epoxy paints based on an interview of the painters at the end of the workshift. Painters who used epoxy paints (mixing, rolling, brushing, or spraying) for more than 15 minutes were classified as "exposed"; all others were classified as 
"non-exposed". All subjects who participated in the study were informed of the risks of spirometry and signed consent forms approved by the Committee on Human Research of the University of California, San Francisco.

\section{EXPOSURE}

An industrial hygiene evaluation was conducted to evaluate work practices and exposures. Various paints were used throughout the ship depending on the performance characteristics required for the coating. Epoxy paints were used in bilges, tanks, engine room, and on decks, hull, and keel. High heat aluminium paints were used on the stacks. The keel was finished with a vinyl antifouling paint. Most other surfaces received an alkyd resin paint.

Epoxy paints were applied in the shipyard by airless spray, brush, and roller. The highest environmental concentrations of epoxy paint probably occurred during tank painting. The tank evaluated was a confined space with hatches at the top and bottom. Air was pumped into the bottom of the tank to speed drying and prevent the formation of explosive atmospheres. Painters typically worked in the tank for about two hours at a time for a total of up to six hours in an eight hour workshift. As much of the tank as possible is sprayed; brush and roller are then used for critical touch up, inaccessible areas, breaks in the coating, and welding burns.

Respiratory protection varied with job title. Spray painters wore full face airline air supplied respirators and various full body coverings. Brush/roller painters wore organic vapour (OV) cartridge half mask respirators with skin protection as necessary. Pot tenders worked outside the tank mixing and supplying paint and assuring air supply to the painters. They kept dual OV cartridge half mask respirators available for use as needed. Helpers, who worked outside the tank doing odd jobs such as collecting supplies, used similar respiratory protection.

Diethylene triamine (DETA) was the curing agent in the applied epoxy paint. Specifically, the epoxy paint hardener contained $94 \%$ aliphatic ketimine (diethylene triamine/methyl isobutyl ketone ketimine adduct with phenyl glycidyl ether) and $6 \%$ DETA. The epoxy resin contained $30 \%$ epoxy resin (epichlorohydrin-based), $7 \%$ solvents (methyl n-amyl ketone, xylene, 2-butoxyethanol), and $63 \%$ pigments (aluminosilicates, titanium dioxide, lead chromate). The other principal paints used on the day of testing were alkyd (enamel) and zinc chromate based.

PULMONARY FUNCTION TESTING

Spirometry was performed on two occasions for each subject by trained technicians who were blind to exposure state. This was done immediately before work (about 0700 for day shift and 1600 for swing shift) and within 30 minutes of the end of work (about 1400 for day shift and 2400 for swing shift).

Spirometry was performed according to American Thoracic Society (ATS) criteria ${ }^{15}$ using two identical volume displacement spirometers (Puritan-Bennett Model VS 400). The spirometers were calibrated with a 3-1 syringe before each pre and post-workshift testing session. Pre and post-shift spirometry for each subject were performed on the same spirometer by the same technician. Values for forced vital capacity (FVC), $\mathrm{FEV}_{1}$, and forced expiratory flow $\left(\mathrm{FEF}_{25 \%}-75 \%\right)$ were hand calculated by a technician who was blind to exposure category. These values were corrected to body temperature and pressure, saturated with water vapour (BTPS), and by the calibration factor determined before each pre and post-workshift testing period. All values were independently recalculated by one of us.

Baseline predicted values were calculated using the equations of Knudson et al $^{16}$; an additional multiplier of 0.85 was applied for black workers. ${ }^{17}$ To examine cross shift changes in pulmonary function between subjects, the \% change across the workshift was calculated for $\mathrm{FEV}_{1}$ and $\mathrm{FEF}_{25 \%-75 \%}$ for each subject as follows:

$$
\begin{gathered}
\text { Percentage change }(\%)=100 \times \\
\text { (post-shift }- \text { pre-shift }) /(\text { pre-shift }+ \text { post-shift }) / 2
\end{gathered}
$$

Before both the pre-workshift and post-workshift pulmonary function testing, participants were interviewed about pulmonary symptoms, smoking, eating, recent upper respiratory tract infections, medicines, and previous day's work; they also completed a standardised questionnaire about respiratory symptoms ${ }^{18}$ to which dermatological and occupational history questions were added. Participants were instructed not to smoke 30 minutes before testing and information about last cigarette smoked was recorded. Each subject's height was measured and chest auscultation was performed by a physician. At post-workshift testing participants were also interviewed about the day's work activities, paints used, and respiratory protective gear worn.

\section{STATISTICAL ANALYSIS}

Exposure was described by two indices: (1) "exposed"-namely, those who used epoxy paints for greater than 15 minutes on the day of testing, or "non-exposed"; and (2) number of hours of exposure to epoxy paints on the day of testing.

The associations between exposure to epoxy paints and cross-workshift decrement in $\mathrm{FEV}_{1}$ and $\mathrm{FEF}_{25 \%-}$ $75 \%$ were evaluated using general linear models. Based on the alternative hypothesis, the one tailed $t$ test was used. The role of other independent variables, such as age, height, and smoking (pack-years), was evaluated by stepwise multiple regression. Because 
of small cell sizes, prevalence of respiratory symptoms was analysed using Fisher's exact probability test.

Power calculations were based on a sample size of 30 in both the exposed and non-exposed groups, an FEV $_{1}$ variance of 0.063 , a $\beta$ of 0.2 , and an $\alpha$ of 0.05 (one sided $t$ test). The minimum detectable difference in $\triangle F^{\prime} V_{1}$ between the exposed group and the nonexposed group was $5 \cdot 3 \%$.

\section{Results}

Of the painters eligible for participation in the crossworkshift evaluation, two declined. Also, two painters were excluded from the study, one with severe COPD and the other with severe bronchitis. Crossworkshift evaluations were completed on 32 painters exposed to epoxy paints and 28 non-exposed painters. Table 1 presents the demographic characteristics of the two groups. The groups were not significantly different in age, height, sex, race, smoking state, shift work, and years employed at the shipyard.

Table 1 also presents the baseline (pre-workshift)

Table 1 Demographic characteristics of participants

\begin{tabular}{lcc}
\hline & $\begin{array}{c}\text { Non-exposed } \\
\text { workers } \\
(n=28)\end{array}$ & $\begin{array}{c}\text { Exposed } \\
\text { workers } \\
(n=32)\end{array}$ \\
\hline Age (y) & $39 \cdot 0$ & $38 \cdot 5$ \\
Height (cm) & $170 \cdot 1$ & $170 \cdot 4$ \\
Sex: & 25 & 27 \\
$\quad$ Men (No) & 4 & 4 \\
Race: & 3 & 5 \\
White (No) & 21 & 23 \\
Black (No) & 12 & 12 \\
Latino (No) & 8 & 8 \\
Current smoker (No) & & 20 \\
Former smoker (No) & 20 & 12 \\
Shift: & 8 & $9 \cdot 2$ \\
$\quad$ Day (No) & $7 \cdot 4$ & 102 \\
Swing (No) & 104 & 102 \\
Duration of employment at the shipyard & & \\
$\quad$ (y) & 106 & 83 \\
FEV (\% predicted) & 84 & \\
FVC (\% predicted) & & \\
FEF & & \\
\hline
\end{tabular}

Table 2 Work practices on day of testing

\begin{tabular}{lcc}
\hline & $\begin{array}{l}\text { Non-exposed } \\
\text { workers } \\
(n=28)\end{array}$ & $\begin{array}{l}\text { Exposed } \\
\text { workers } \\
(n=32)\end{array}$ \\
\hline Enclosed space & 6 & 25 \\
Open spacet & 22 & 7 \\
Spray painting & 9 & 15 \\
Brush or roll painting & 11 & 13 \\
Pot tending & 4 & 3 \\
Other & 4 & 1 \\
Airline respirator & 0 & 11 \\
Half mask cartridge respirator & 21 & 20 \\
No respiratory protection & 7 & 1 \\
\hline
\end{tabular}

$\star$ Painting in tanks, bilges, or compartments.

tPainting deck, hull, or cargo hold. spirometry results. Baseline $\mathrm{FEV}_{1}, \mathrm{FVC}$, and $\mathrm{FEF}_{25 \%-75 \%}$ werenot significantly different between the exposed and non-exposed painters.

Table 2 lists participant work practices on the day of testing. More exposed painters worked in confined spaces, such as tanks, bilges, and compartments, than non-exposed painters. Exposed painters were also more likely to use spray paint equipment. Almost all of the exposed painters wore some form of respiratory protective gear on the day of testing. More than half wore OV cartridge respirators and roughly one third wore positive pressure air supplied respirators. On the other hand, a quarter of the nonexposed painters wore no respiratory protective gear and the rest wore $\mathrm{OV}$ cartridge respirators.

The figure shows the frequency distribution of painters by hours of exposure to epoxy paints. Exposed painters used epoxy paints for an average of six hours on the day of testing.

Table 3 presents the prevalence of respiratory symptoms experienced by participants on the day of testing. The prevalence of any lower respiratory symptoms was greater among painters exposed to

Table 3 Prevalence of respiratory symptoms experienced during the workshift

\begin{tabular}{lll}
\hline & $\begin{array}{l}\text { Non-exposed } \\
\text { workers } \\
(n=28)\end{array}$ & $\begin{array}{l}\text { Exposed } \\
\text { workers } \\
(n=32)\end{array}$ \\
\hline Any upper respiratory symptoms & 5 & 12 \\
Eye itch & 1 & 6 \\
Red eye & 1 & 2 \\
Sore throat & 3 & 8 \\
Nasal congestion & 1 & $7^{\star}$ \\
Any lower respiratory symptoms & 6 & $15^{\star}$ \\
Cough & 6 & 10 \\
Wheezing & 0 & 3 \\
Shortmess of breath & 0 & $6^{\star}$ \\
Chest tightness & 1 & 3 \\
\hline
\end{tabular}

ॠFisher's exact test, $\mathrm{p}<0.05$.

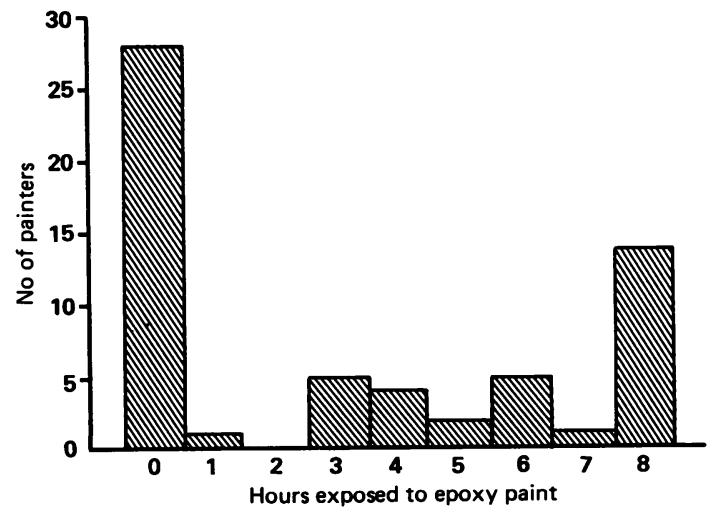

Figure Distribution of No of painters by hours of exposure to epoxy paint. 
Table 4 Mean cross workshift change in $F E V_{1}$ and $F E F_{25 \%-75 \%}$

\begin{tabular}{llll}
\hline & Non-exposed workers $(n=28)$ & Exposed workers $(n=32)$ & $p$ Value \\
\hline Mean change in $\mathrm{FEV}_{1}(\mathrm{SEM})$ & $-1 \cdot 4 \%(1 \cdot 0 \%)$ & $-3 \cdot 4 \%(1.0 \%)$ & $0 \cdot 07$ \\
Mean change in $\mathrm{FEF}_{25 \%-75 \%}(\mathrm{SEM})$ & $-3.0 \%(2 \cdot 9 \%)$ & $-6.2 \%(2.7 \%)$ & $0 \cdot 22$ \\
\hline
\end{tabular}

*One sided, $t$ test.

epoxy paints $(p<0.04)$ than among non-exposed painters.

Chest auscultatory findings were not significantly different between the exposed and non-exposed painters. At the beginning of the shift, chest auscultation detected wheezing on forced exhalation in one painter. At the end of the workshift, wheezing on forced exhalation was detected in two painters exposed to epoxy paints and in one painter using a chlorinated rubber paint. Crackles or rhonchi were detected in three painters exposed to epoxy paints but were not detected in any of the non-exposed painters.

Table 4 presents the mean cross workshift changes in $\mathrm{FEV}_{1}$ and $\mathrm{FEF}_{25 \%-75 \%}$ for exposed and non-exposed participants. The mean change in $\mathrm{FEV}_{1}$ in the nonexposed group was $-1.4 \%(\mathrm{SEM}=1.0 \%)$ compared with $-3.4 \%($ SEM $=1.0 \%)$ in the exposed group $(p=0.07)$. The range of cross workshift change of $\mathrm{FEV}_{1}$ in the non-exposed group was $-12 \cdot 1 \%$ to $+13.5 \%$ and the range in the exposed group was $-21 \%$ to $+5 \cdot 4 \%$.

One painter experienced a cross workshift $\mathrm{FEV}_{1}$ drop of more than $20 \%$ on the day of testing. He applied epoxy paints in tanks with a brush and roller for eight hours and reported using a cartridge respirator for the full eight hours. In three painters the cross workshift $\mathrm{FEV}_{1}$ dropped between 10 and $15 \%$. Two painted inside tanks with epoxy paints for four hours; one spray painted and the other brush painted. The third brush painted compartments with enamel paint for four hours.

Linear regression analysis on the cross workshift change in $\mathrm{FEV}_{1}$ was performed with "hours of exposure to epoxy paints" as the independent variable. A statistically significant decline in $\mathrm{FEV}_{1}$ occurred with increasing hours of exposure to epoxy paints $(p=0.05)$. The correlation coefficient $\left(R^{2}\right)$ was $0 \cdot 04$.

\section{Discussion}

Previous reports evaluating the pulmonary effects of epoxy resin systems have been limited to case reports and small cross sectional studies. Case reports confirmed with inhalation challenge tests have documented both immediate and delayed bronchoconstriction. In these reports asthma has always been associated with the curing agent and not the epoxy resin. ${ }^{19-25}$ Sargent and coworkers reported a greater cross shift drop of $\mathrm{FEV}_{1}$ in ski assemblers exposed to 3-(dimethyl- amino)propylamine, an epoxy curing agent, than in controls. ${ }^{12}$ These investigators followed up the exposed ski assemblers for two years and noted a larger than expected drop in baseline FEV until a local ventilation system was installed. ${ }^{13}$

Although the number of participants in the present study was small and the power of the study to detect differences between painters exposed and painters not exposed to epoxy paints was low, certain patterns emerged. Firstly, the findings suggest that shipyard painters using epoxy paints have a greater fall in $\mathrm{FEV}_{1}$ over a workshift than shipyard painters who do not use epoxy paints. These findings are bolstered by the finding that the degree of drop in $\mathrm{FEV}_{1}$ increases with increasing number of hours of exposure to epoxy paints. Furthermore, the prevalence of lower respiratory tract symptoms was significantly greater among painters exposed to epoxy paints than those not exposed.

In the case reports mentioned above, epoxy resin systems have been associated with delayed bronchoconstriction. It is possible, therefore, that measuring pulmonary function at the end of the workshift may not have detected the nadir of pulmonary function. A more sensitive method of following pulmonary function would be to have subjects perform serial peak expiratory flow measurements after they leave work.

Although the number of hours of exposure to epoxy paints did not explain much of the variance of $\triangle \mathrm{FEV}_{1}$, hours of exposure to epoxy paints may not be the best index of exposure. Unfortunately, it was not possible to measure environmental concentrations of DETA; nor was it possible to evaluate other factors which will influence exposure, such as type and frequency of respirator use and adequacy of fit.

Although subjects were informed that the purpose of the study was to evaluate the effects of painting on pulmonary function they were not informed of the specific hypothesis to be tested. Also, the painters did not know until the day of testing which paints they would be using. The effect of recall bias on symptom reporting should have been small, as the painters did not know that epoxy paints were the target of the study and were interviewed about symptoms immediately at the end of the workday.

In normal and asthmatic people lung function, as measured by peak expiratory flow, has a diurnal rhythm..$^{26}$ The peak in lung function is between 3.00 and $4.00 \mathrm{pm}$ and the trough is between 3.00 and 
$4.00 \mathrm{am}$. The magnitude of this fluctuation in normal subjects is between $5 \%$ and $10 \%$. Therefore, an improvement in lung function across the workshift would have been expected in the day shift; instead a decline occurred in both the exposed group and the control group. The decline in the control group may have been due to exposure to other respiratory tract irritants such as other paints, solvents, dusts, or welding fumes. If the control group was exposed more to irritant fumes than the exposed group, the study would be biased toward underestimating the decline due to exposure to epoxy paint.

Based on our findings, we recommend that when epoxy resin coatings are used in the shipyard setting, a comprehensive health and safety plan be implemented that covers training, respiratory protection, medical surveillance (including annual cross workshift spirometry), and medical removal or transfer. Painters experiencing job related respiratory symptoms, skin rash, or significant cross workshift decrements in $\mathrm{FEV}_{1}$ should undergo further medical evaluation. Painters with asthma or allergic contact dermatitis due to epoxy paints should be offered work where minimal potential for exposure to epoxy paints exists.

The results of our present study are consistent with previous evaluations of workers exposed to epoxy resin systems, and suggest that exposure to epoxy paints can contribute to a short term decline in pulmonary function. Further epidemiological studies, preferably of a prospective design, are, however, needed to confirm the suggestive findings of this study.

Technically, the results are generalisable only to other shipyards with similar work practices and respiratory protection programmes. Our recommendations can be reasonably extended to other industrial settings, however, where epoxy resin coatings are used, such as the coating of utility, heating, and air conditioning equipment.

We thank Leo Blade and Lynnette Jolliffe (National Institute of Occupational Safety and Health), Brona Mae Mullican, Maurice Hiatt, and Dorothy Christian (University of California, San Francisco) for assistance with industrial hygiene and spirometry, and Jim Bellows, Sonya Echaverria, Neil Maizlish, PhD, Mitchell Shandling, and Glen Shorr, MPH (California Occupational Health Program) for assistance with industrial hygiene, statistical analysis, and worker notification. We also thank the management of the shipyard and the union for their cooperation. Finally, without the voluntary participation of the painters at the shipyard (Local 9, Industrial Union of Marine and Shipbuilding Workers of America), this study would not have been possible.
Requests for reprints to: Dr D Rempel, San Francisco General Medical Center, Building 30, Fifth Floor, 1001 Portero Avenue, San Francisco CA 94110 , USA.

1 Birmingham D. Clinical observations on the cutaneous effects associated with curing epoxy resins. American Medical Association Archives of Industrial Health 1959;19:365-7.

2 Fregert $S$, Thorgiersson A. Patch testing with low molecular oligomers of epoxy resins in humans. Contact Dermatitis 1977;3:301-3.

3 Thorgiersson A. Sensitization capacity of epoxy resin hardeners in the guinea pig. Acta Dermato Venereol 1978;58:332-6.

4 Dahlquist I, Fregert S. Allergic contact dermatitis from volatile epoxy hardeners and reactive diluents. Contact Dermatitis 1979;5:406-10.

5 Niinimaki A, Hassi J. An outbreak of epoxy dermatitis in insulation workers at an electric power station. Dermatosen Beruf Umwelt 1983;31:23-5.

6 Suhonen R. Epoxy-dermatitis in a ski-stick factory. Contact Dermatitis 1983;9:131-3.

7 Putten van PB, Coenraads PJ, Nater JP. Hand dermatoses and contact allergic reactions in construction workers exposed to epoxy resins. Contact Dermatitis 1984;10:146-50.

8 Blanken R, Nater JP, Veenhoff E. Protective effect of barrier creams and spray coatings against epoxy resins. Contact Dermatitis 1987;16:79-83.

9 Jolanki R, Estlander R, Kanerva L. Contact allergy to an epoxy reactive diluent: 1,4-butanediol diglycidyl ether. Contact Dermatitis 1987;16:87-92.

10 Joost TH. Occupational sensitization to epichlorohydrin and epoxy resin. Contact Dermatitis 1988;19:278-80.

11 Tosti A, Guerra L, Toni F. Occupational airborne contact dermatitis due to epoxy resin. Contact Dermatitis 1988; 19:220-3.

12 Sargent EV, Mitchell CA, Brubaker RE. Respiratory effects of occupational exposure to an epoxy resin system. Arch Environ Health 1976;31:236-40.

13 Brubaker RE, Muranko HJ, Smith DB, Beck GJ, Scovel G. Evaluation and control of a respiratory exposure to 3 (dimethylamino) propylamine. J Occup Med 1979;21:688-90.

14 American Thoracic Society. Evaluation of impairment disability secondary to respiratory disorders. Am Rev Respir Dis 1986;133:1205-9.

15 American Thoracic Society. Standardization of spirometry 1987 update. Am Rev Respir Dis 1987;136:1285-98.

16 Knudson RJ, Lebowitz MD, Holberg CJ, Burrows B. Changes in the normal maximal expiratory flow-volume curve with growth and aging. Am Rev Respir Dis 1983;127:725-34.

17 Horvath EP, Frostman TO. NIOSH spirometry workbook. Cicinnati: US Department of Health and Human Services, National Institue for Occupational Safety and Health, 1980.

18 Ferris BG. Epidemiology standardization project. Am Rev Respir Dis 1978;118:1-53.

19 Fawcett IW, Taylor N, Pepys AJ. Asthma due to inhaled chemical agents-epoxy resin systems containing phthalic acid anhydride, trimellitic acid anhydride and triethylene tetramine. Clin Allergy 1977;7:1-14.

20 Ryan G, Cartier A, Bandouvakis J, Hall D, Dolovich J, Hargreave FE. Occupational asthma due to diethylene triamine. Am Rev Respir Dis 1980;121:253.

21 Rivera M, Nicotra B, Byron GE. Trimellitic anhydride toxicity. Arch Intern Med 1981;141:1071-4.

22 Vallieres M, Cockcroft DW, Taylor DM, Dolovich J, Hargreave FE. Dimethyl ethanolamine-induced asthma. Am Rev Respir Dis 1977;115:867-71.

23 Durham SR, Davies S, Venables K, Graneek B, NewmanTaylor AJ. Occupational asthma in a bathtub resurfacer due to pentamethylene diethylene triamine. Thorax 1986;41:251.

24 Lam S, Chan-Yeung $M$. Ethylenediamine-induced asthma. Am Rev Respir Dis 1980;121:151-5.

25 Ward MJ, Davies D. Asthma due to grinding epoxy resin cured with phthallic anhydride. Clin Allergy 1982;12:165-8.

26 Clark TJH. Diurnal rhythm of asthma. Chest 1987;91(Supplement): $137-41$.

Accepted 4 March 1991 